\title{
The Application of Cognitive Linguistic Theories to English-Chinese Translation
}

\author{
Xiaogen Liao \\ Sichuan International Studies University, Chongqing, China \\ Email: 13508371062@163.com
}

How to cite this paper: Liao, X. G. (2018). The Application of Cognitive Linguistic Theories to English-Chinese Translation. Open Journal of Modern Linguistics, 8, 61-69.

https://doi.org/10.4236/ojml.2018.83008

Received: April 2, 2018

Accepted: June 24, 2018

Published: June 27, 2018

Copyright $\odot 2018$ by author and Scientific Research Publishing Inc. This work is licensed under the Creative Commons Attribution International License (CC BY 4.0).

http://creativecommons.org/licenses/by/4.0/

\begin{abstract}
In recent years, Cognitive Translatology, a new frontier subject, has been established after the interaction of Cognitive Linguistics with Translatology. Aiming to further the development of Cognitive Translatology, this paper investigates the application of major theories in cognitive linguistics to Chinese-English translation practice, including Prototype Category Theory, Conceptual Metaphor Theory, Conceptual Metonymy Theory, Iconicity Theory and Figure-Ground Theory. It is found that these theories have strong explanatory power and instructive significance for translation practice.
\end{abstract}

\section{Keywords}

Cognitive Linguistics, Cognitive Translatology, Translation Process, English-Chinese Translation

\section{Introduction}

Having enriched itself by resorting to theories of different disciplines like linguistics, literature, philosophy, the translatology has constructed multiple translation theories, and has achieved rapid development in recent decades (Wang, 2014). Cognitive Linguistics, currently, has flourished and its theoretical applications have extended to translatology. We searched for papers from China National Knowledge Internet, the largest database on journal articles in China, using "Cognitive Linguistics" plus "translation" as key words. The total number of papers is more than 200 in the last five years. Among those studies, theories of Cognitive Linguistics applied to Translatology mainly encompass Prototype Category Theory (He, 2016; Gong, 2010), Construal Theory (Tan, 2016; Qiao, 2014; Sun, 2016), Metonymy and Metaphor Theory (Wang, 2014; Liang, 2013; Lu, Wang \& Qin, 2014), Figure-Ground Theory (Li \& Zhang, 2016), etc. The 
translated texts are diverse, mainly including advertisements, literary works, film titles, medical terminologies. Based on the aforementioned predecessors' explorations, this paper tries to string the scattered theories above into a single line and apply it to Chinese-English translation practice, aiming to enrich the cognitive linguistic approach to cognitive translation studies and to provide guidance for translators or translation researchers. We pay special attention to translation between Chinese and English from the perspective of Cognitive Linguistics, with the purpose of enriching and perfecting the research achievements of Chinese translation theories on the one hand, and of providing referential and complementary contents for western translatology theories on the other hand.

\section{Cognitive Linguistic Theories and English-Chinese Translation}

\subsection{The Prototype Category Theory}

Admittedly, the equivalence between target language and source language has long been enshrined by translators. It can be said that the concept "equivalence" guides the development of western translation theories. Dynamic and Equivalence (Nida, 1964: p. 159), Textual Equivalence (Catford, 1965: pp. 20-21), Communicative Equivalence (Nord, 2001: p. 9), Retention of Translation Invariance at Content Level (Kade, 1968), Functional Equivalence (de Waar \& Nida, 1986), Pragmatic Equivalence (Baker, 1992: p. 217), all these theories run through the long history of translation. Although translators often set their minds on the equivalence between target text and source text, absolute faithfulness or equivalence is no more than a utopian fantasy due to language differences, as well as cognitive differences between the translator and the author.

Translation researchers have demonstrated translation equivalence from the perspective of interlingual expression differences or cultural and psychological differences, far from deep probe into the cognitive mechanism of thinking $(\mathrm{He}$, 2016). Resorting to the Prototype Category Theory in cognitive linguistics, we can break free from the static language view in the Equivalence Theory, thus going out of the impasse of absolute equivalence. The Prototype Category Theory is one of main theories in Cognitive Linguistics. The properties of category are the result of human's functional embodiment in specific physical and social environments (Lakoff, 1987: p. 12). Therefore, the author and the translator in different environments are presumably different in terms of category.

In Construal on Translation Equivalence from the Perspective of Prototypical Category Theory, $\mathrm{He}$ (2016) pointed that absolute equivalence is rare or none-existent and there is just a series of Equivalence Cluster. The members of the core concept representation in the Equivalence Cluster were called Prototypical Equivalent, while members established with prototypical equivalents were defined as Non-typical Equivalent. As we know, there often exists a one-to-many mapping relationship between source language and target lan- 
guage, and every member among the exact equivalents of source language shares one or more attributes, similarly connecting together and forming a category. According to the Family Resemblance Theory, all meaningful items with family resemblance can be acceptable counterparts of a certain prototype concept.

To illustrate the ideas above, we take the Chinese translation of the word "maid" in the third line of the first stanza of Wordsworth's poem Lucy as an example. This paper makes a comparative analysis on the 43 translations with a total of 12 corresponding translations of the word "maid" (see Table 1, translations into demonstrative pronouns are excluded from the analysis). Among the 12 translations, “姑娘” and “少女” are the most typical, followed by “佳人”, and all the rest appear only once. From the frequency distribution of Chinese translation of “maid “ in Lucy, it is apparent that “姑娘” and “少女” are prototypical equivalents of "maid", while the others are its non-typical equivalents. Both prototypical equivalents and non-typical equivalents can be regarded as acceptable translation equivalents of the word "maid", together forming a equivalence cluster (see Figure 1). In this cluster, the status of each pair of equivalents (category members) is not equal. The prototypical equivalents (center members or prototype) are “姑娘” and “少女”, and the others are non-typical equivalents (peripheral members). Referring to prototypical equivalents, the non-typical equivalents aggregate into a cluster according to its family resemblance to prototypical equivalents.

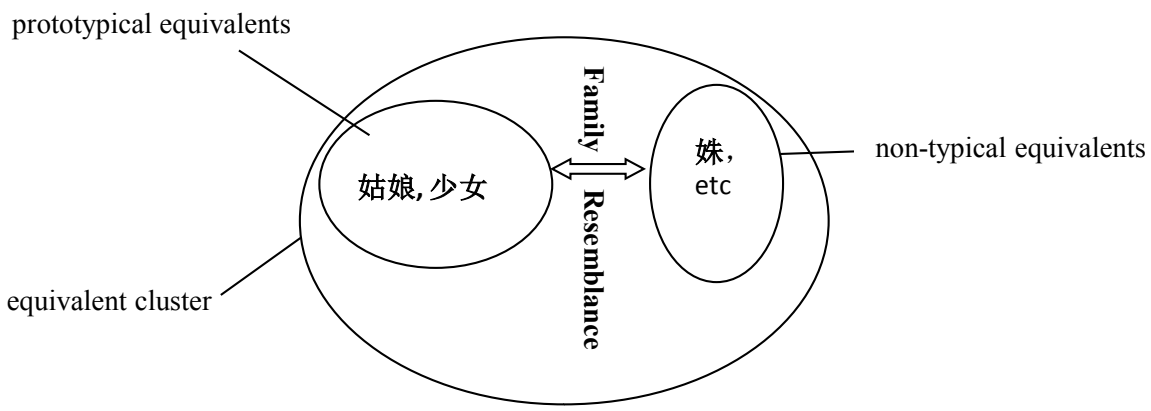

Figure 1. Different translations' construal of "maid" from the perspective of the prototype theory.

Table 1. Frequency distribution of Chinese translation of "maid" in Lucy.

\begin{tabular}{ccccccccc}
\hline $\mathrm{n}$ & Chinese & Fre. & $\mathrm{n}$ & Chinese & Fre. & $\mathrm{n}$ & Chinese & Fre. \\
\hline 1 & (小) 姑娘 & 13 & 5 & 女人 & 1 & 9 & 女仆 & 1 \\
2 & (妙龄) 少女 & 7 & 6 & 女 & 1 & 10 & 伊人 & 1 \\
3 & 佳人 & 4 & 7 & 女郎 & 1 & 11 & 丽人 & 1 \\
4 & 红颜 & 1 & 8 & 姝 & 1 & 12 & 美 & 1 \\
\hline
\end{tabular}

Translations from: http://blog.sina.com.cn/s/blog_667242870100p9a9.html. 


\subsection{The Conceptual Metaphor and Metonymy Theory}

Metaphors and Metonymies are omnipresent, and they are even what humans live by. Cognitive Linguistics claims that people develop basic concepts after interacting with the world through the body and space, and then extend them to other conceptual domains (especially abstract concept domains) through metaphor and metonymy mechanism, thus forming the complex conceptual system of human today (Wang, 2012). Suffice it to say, the application of metaphor mechanism and metonymy mechanism is indispensable for translators.

According to the Conceptual Metaphor Theory (CMT), the conceptual system which human's thought and action rely on is metaphorical in nature. The process of human's thinking is that we understand or express a concept by another concept (Zhang, 2012). Martín (2010: p. 171) held a notion that conceptual metaphor is of great importance to the theoretical development of translatology. Recently, Chinese scholars have used the CMT to guide translation practice. Liang (2013), for example, based on this theory, comprehensively analyzed the English translation (by Ge Haowen) of Mo Yan's novel “Big Breasts and Wide Hips". Tian (2016) explored the influence and mechanism of the CMT in the field of cultural translation of political discourse through the study of English translation in Chinese government work report in 2012. Furthermore, translation studies based on this theory also involve other genres, such as poetry and scientific texts.

In the famous saying "Money is lens in a camera" by J. T. Adams, there is a systematic equivalence between source domain (lens) and target domain (money). The camera lens are capable of mirroring a person's appearance, and money can also test or reflect one's quality. Such a metaphorical expression, therefore, has cross-cultural consistency. In other words, one metaphorical process is enough for both English and Chinese to express or translate the concept. However, social, cultural, cognitive and psychological differences may exert influence on people's conceptual thinking, resulting in a big gap among the metaphors in different languages. The utterance "He is full of beans" is frequently used in English to describe a person as "energetic". Obviously, the metaphorical mechanism of "referring to abstract concepts in concrete states (events)" operates in the utterance.

Compared with metaphor, metonymy is a more basic cognitive model in human conceptual system. The conceptual metonymy, as a primary human's thinking paradigm and cognitive mechanism, has permeated into all levels of language. Wang (2012) points out that most English and Chinese words have a overlapping feature, namely, partially equivalent meaning, which is the cognitive basis for the metonymy mechanism of Part for Whole, Part for Part and Whole for Part. It is imperative that translators should also fully recognize the metonymy mechanism of the source language. In the statement, for instance, "Great minds think alike", the translators should be aware of its metaphorical pattern of “Part for Whole”, so they should not translate it into “伟大的脑袋想法相似”, 
but “英雄所见略同”.

Also, in the forty English translations of $A$ Spring Morning (a famous ancient Chinese poem by Meng Haoran), the translators rendered “落叶” into various English expressions, encompassing be fallen, have fallen, fell, fall, dropped, have been brown to ground, be gone, ect. Despite a variety of translation forms, all can be categorized into process and result. The feature of "salience" of conceptual metonymy is reflected here, so the mechanism of metonymy is embodied in the process of translation.

\subsection{Construal Theory}

The semantic view of cognitive linguistics considers that all meanings of linguistic units and all evaluations of language expressions are relevant to the context, and one essential aspect of meaning is the conception related to the context (physics, society and language environment), namely construal (Tan, 2016). The Construal Theory (CT) has five basic elements, including perspective, scope, background, prominence and specificity.

The Perspective can be regarded as a reference point of cognition. Indubitably, when perceiving things, we first choose a specific cognitive reference point. Just like the motion of objects in real world, all movements are relative and their states depend on the reference point. We understand things in the same way, and the cognitive reference point determines our cognitive approach, thus influencing our language expressions. Therefore, different translators often produce different linguistic expressions when understanding the source language. For example, if describing a half bottle of water, some are likely to construe as "The bottle is half-full", while others may construe as "The bottle is half-empty".

In a broad sense, the scope and background in the CT can be understood as the contextual scope of translation activities, and in a narrow sense as translators' activation of the concept domain category in cognitive construal activity (Shun, 2016). In the 44 different translation versions of Tennyson's "Man for the field and woman for the hearth" (selected from Feng, 2002: pp. 222-226), "man" and “woman” are respectively construed as “男人, 夫, 男, 强汉, 男儿, 丈夫, 哥哥, 牛郎, 君”, and “女, 妇, 巧妇, 妹妹, 荆钗, 妾”. The differences in multiple versions are the result of the different categories of conceptual domains in which the translator activates cognitive construal activities in the process of translation. Anyway, the scope and background should maximize proximity to the original text in consideration of faithfulness.

After determining the scope and perspective, we should consider which aspect of things should be focused on to highlight the characteristics of them. In the forty English translations of $A$ Spring Morning above-mentioned, prominence can also be well reflected. the translators rendered “落叶” into various English expressions, encompassing be fallen, have fallen, fell, fall, dropped, have been brown to ground, be gone, ect. Despite a variety of translation forms, the essence is nothing more than their prominence difference: process or result. 
Finally, translators sometimes subconsciously simplify their language and information. Of course, they are likely to describe some relevant information in detail by adding background information. Be simpler or more explicit, all are the manifestation of specificity in construal, coinciding with the amplification and omission method in translation. Suffice it to say, the option of specificity in translation is the result of translator's construal on the source text emphasis.

\subsection{Iconicity Theory}

Cognitive Linguistics claims that the connection between language form and meaning is not absolutely arbitrary, and that language has its motivation and iconicity. Cognitive linguists has probed into the iconicity from different levels, ranging from the phonetic and lexical level to the syntactic and textual level.

The iconicity of the lexical level is mainly reflected in the phonetic and form iconicity. For example, the advertising slogan of Harajuku Lovers perfume "You got the wicked style. I like the way what you are. I am your biggest fans" is translated into “你们的风格如此涺异, 是我的挚爱毫无异议, 崇拜你们五体 投地”. In the source text, the third word (wicked, way, biggest) in each sentence of the English advertising slogan has a same syllable /i/. The vowel repetition in word-initial and or word-medial is an assonance, which is similar to the Chinese vowel rhyme, namely, two or more characters with the same vowel formation. This is a way to link up the related words, simultaneously creating the musical beauty. Similarly, the last word of each sentence (异, 议, 地) in the translation is also in rhyme. Concurrently, parallelism is used, creating the beauty of form and sound and achieving the same effect as the source text. The adaptation at the phonological level is also the embodiment of iconicity.

With the continuous development of the iconicity theory, scholars have refined the theory at the syntactic level and proposed distance iconicity, order iconicity, quantity iconicity, marked iconicity, etc. These iconicity theories actually to some degree enlighten translators. First, Distance iconicity, for instance, can tell the difference between expressions such as "give somebody something" and "give something to somebody", as well as "help somebody to do something" and "help somebody do something". Thus translators or Chinese EFL learners will no longer consider a synonymous sentence pair as an equivalent. Second, sequential iconicity refers to a fact that the order in which linguistic units are arranged is similar to the natural temporal order. Admittedly, order iconicity is an important distinguishing characteristic between Chinese and English. Chinese sentences often conform to the time sequence of event, while English thinks it as optional (Wang, 2016). Therefore, translators should fully consider this point during the process of English and Chinese translation. The sentence, for example, “小分队跳下绝壁岩, 续行三日, 进入绥芬大甸子” (Three days after the detachment descended the cliff, it reached the Suifen Plain") (from Linhai Snowfield, a book by Qu Bo). Expressly, events are presented one after another according to the time of their occurrence in the Chinese source text, while its corresponding English target text takes event sequence into no consideration. 
Third, Quantitative iconicity refers to the consistency between the quantity of language expression form and the quantity of the real world (Ungerer \& Schmid, 1996: p. 252). Reduplicative words, as a manifestation of quantity iconicity, are commonly used in Chinese poetry. Judging from the economical principle of language, we can presume that reduplicative words must have their special pragmatic meaning value in the condition of violating the principle. Translators should take this into full consideration in case the original meaning of source language attrition. Take two famous lines by $\mathrm{Du} \mathrm{Fu}$, a great Chinese poet in Tang Dynasty一 “无边落木萧萧下, 不尽长江滚滚来”. The Chinese translation master $\mathrm{Xu}$ Yuanchong rendered the two lines into "The boundless forest sheds its leaves shower by shower, The endless river roll its waves hour after hour", taking full account of the principle of quantitative iconicity.

\subsection{The Figure-Ground Theory}

The Figure-Ground theory originated from psychology, and it raised cognitive linguists' attention subsequently. This theory is a basic cognitive principle that language organizes the conceptual contents. Among it, "Figure" can be understood as a kind of "embellishment", which is the prominent part of cognitive concept or perception, that is, the focus part of attention; and "Ground" is "embellished object", namely, the part that is highlighted and serves as a foil to the figure.

The relationship of "highlighting and highlighted, foiling and foiled" between Figure and Ground, is appropriately applied to interpret literary works by cognitive poetics, especially in the interpretation for artistic conception construction of poems (Liang \& Chen, 2008). In this way, this theory can also provide theoretical guidance for translating the artistic conceptions and images in poems. Next, this paper will interpret $\mathrm{Xu}$ Yuanchong's translation for "jiangxue" (an ancient prose by Liu Zhongyuan) from the perspective of Figure-Ground Theory.

Source text: 千山（G）鸟飞（F）绝, 万径（G）人踪（F）灭。孤舟（G） 莒笠翁 $(F)$, 独钓寒江雪 $(G)$ 。

Target text (Xu Yuanchong): From hill to hill (G) no bird (F) in flight, From path to path $(\mathrm{G})$ no man $(\mathrm{F})$ in sight. A straw-cloaked man $(\mathrm{F})$ afloat, behold! Is fishing snow on river cold $(\mathrm{G})$.

From the first two lines of the poem, it is obvious that "mountain" belongs to the "Figure" (abbreviated as "P"), and "bird" belongs to Ground (abbreviated as “G”). The author uses the words jue (绝) and mie (灭) to shift the reader's visual focus from figure to ground, and to the mountains without birds flying over, and the paths without pedestrians passing by, creating an atmosphere of extreme solitude. It is not difficult to imagine the author's loneliness and despair. In the last two sentences of the poem, zhou (舟) and jiangxue (江雪) are the Ground, and shuoliweng (蔈笠翁) the Figure. The fishing man's loneliness and dreariness can be seen particularly conspicuous in the background of river snow. The Xu's translation fully corresponds to the source text and draws the same landscape 
painting as the source text.

\section{Conclusions}

To encapsulate, the translatology and Cognitive Linguistics have established a coupling relationship through Cognitive Translatology. Cognitive linguistics, on the one hand, injects new blood into translation studies, and translatology also promotes the advancement of cognitive linguistics. This paper discusses the application of major cognitive linguistic theories to translation practice, including Prototype Category Theory, Conceptual Metaphor Theory, Conceptual Metonymy Theory, Iiconicity Theory and Figure-Ground Theory. It is found that these theories have strong explanatory power and instructive significance for translation practice.

Of course, there are also some limitations in this article. First of all, due to the limited space and the author's knowledge, this paper only expounds upon the application of some common theories in cognitive linguistics to translation practice, and it still merits our attention whether other cognitive linguistic theories can be applied to translation practice, such as Construction Theory, Frame theory, Embodied Cognition Theory. Secondly, in terms of theoretical application, this paper only cited some typical examples contributing to our arguments, and it still faces a challenge that whether these theories have their universality.

After all, by reviewing the relevant literature, this paper finds that most of Chinese studies on cognitive process and acquisition competence are still at the theoretical level, and empirical studies are rare. But the international cognitive translation research is in full swing. Wang (2014) holds that Cognitive Translatology at present should follow the road of "Up-and-down Connection", i.e. it should, based on translation studies, go up to the metaphysical theory level on the one hand, and on the other hand step down to the "hypophysical" experiment level. Only by the realization of "three-in-one" goal can Cognitive Translatology go further.

\section{Acknowledgements}

This study was supported by Postgraduate Research Project of Sichuan International Studies Universities (SISU2017YY07). We thank the reviewer and Professor Meng Jiang for their inspiring comments and suggestions on previous versions of this manuscript.

\section{References}

Baker, M. (1992). In Other Words : A Coursebook on Translation. Routledge. https://doi.org/10.4324/9780203327579

Catford, C. (1965). A Linguistic Theory of Translation. London: Oxford University Press. de Waar, J., \& Nida, E. A. (1986). From One Language to Another: Functional Equivalence in Bible Translating. Nashville: Thomas Nelson.

Feng, Q. Y. (2002). A Practical Course Book on Translation. Shanghai: Shanghai Foreign 
Language Education Press.

Gong, X. B. (2010). Switching between Chinese and English Set Phrases: A Prototype Theory-Based Perspective. Shandong Foreign Language Teaching Journal, 31, 104-107.

He, A. J. (2016). Construal on Translation Equivalence from the Perspective of Prototypical Category Theory. Foreign Language Education, 37, 107-110.

Liang, X. H. (2013). The Translation of Thematic Images in Big Breasts and Wide Hips: On Howard Goldblatt's Translation of Conceptual Metaphors. Foreign Language and Literature, 29, 93-99.

Martín, R. M. (2010). On Paradigms and Cognitive Translatology. Translation and Cognition. https://doi.org/10.1075/ata.xv.10mun

Nida, E. (1964). Toward a Science of Translating. Leiden: Brill.

Nord, C. (2001). Translating as a Purposeful Activity: Functionalist Approaches EXplained. Shanghai: Shanghai Foreign Language Education Press.

Qiao X. L. (2014). English Translation of A Dream of Red Mansions (The Story of the Stone) Analyzed from the Perspective of Cognitive Grammar. Shanghai Journal of Translators, 4, 73-76.

Tan, Y. S. (2016). A Construal-Centered Cognitive Approach to Understand Translation Competence. Chinese Translators Journal, 5, 15-22.

Tian, M. (2016). The English Translation Research of the Government Report in 2015 Based on Conceptual Metaphor. Heilongjiang Researches on Higher Education, 6, 157-160.

Ungerer, F., \& Shmid, H. (1996). An Introduction to Cognitive Linguistics. London: Longman.

Wang, Y. (2012). Cognitive Translatology. Chinese Translators Journal, 4, 17-23.

Wang, Y. (2014). Cognitive Translatology: Theories and Methods. Foreign Languages and Their Teaching, 2, 1-8.

Wang, Y. (2016). ECM \& Iconicity of Temporal Sequence in Translation: The 11th Paper on Cognitive Translatology Exploration. Shandong Foreign Language Teaching Journal, 37, 3-11.

Zhang, X. (2012). Permanent Metaphor: A Study on Pound's Translation of Metaphors in the Perspective of the Conceptual Metaphor Theory. Journal of East China Normal University (Philosophy and Social Sciences), 44, 144-149. 